Supporting Information

\title{
Construction of Synthetic Microbial Ecosystems and the Regulation of Population Proportion
}

Wei Jiang, Xiaoya Yang, Fei Gu, Xiaomeng Li, Sumeng Wang, Yue Luo, Qingsheng Qi*, Quanfeng Liang*

State Key Laboratory of Microbial Technology, Shandong University, Qingdao, China

Tel: $+86-532-58631580$

Postal code: 266000

E-mail: Quanfeng Liang: liangquanfeng@sdu.edu.cn;

Qingsheng Qi: qiqingsheng@sdu.edu.cn

KEYWORDS: synthetic ecosystems, competition, symbiosis, population proportion regulation, microbial consortia 
Supplementary Table S1. Strains used in this study

\begin{tabular}{|c|c|c|}
\hline Strains & Relevant characteristics & References \\
\hline DH5a & 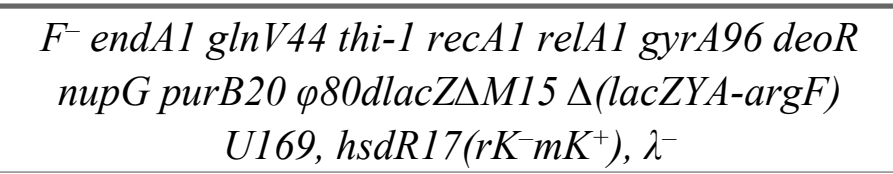 & TransGen \\
\hline TOP10 & $\begin{array}{c}F^{-} \text {mcrA } \Delta(\text { mrr-hsdRMS-mcrBC) } \varphi 80 l a c Z \Delta M 15 \\
\Delta l a c X 74 \text { nup G recA1 araD139 } \Delta(\text { ara-leu }) 7697 \\
\text { galE15 galK16 rpsL }\left(\text { Str }^{R}\right) \text { endA1 } \lambda^{-}\end{array}$ & TransGen \\
\hline TOP10-GFP & $\begin{array}{l}\text { TOP10 derivative, } g f p \text { integrated into the genome at } \\
\text { attp }\end{array}$ & This study \\
\hline TOP10-RFP & $\begin{array}{l}\text { TOP10 derivative, } \mathrm{r} f p \text { integrated into the genome at } \\
\text { attp }\end{array}$ & This study \\
\hline CG01 & $\begin{array}{l}\text { TOP10-GFP harboring pTra*-CcdA-C1 and pLas- } \\
\text { CcdB-C }\end{array}$ & This study \\
\hline CG02 & $\begin{array}{l}\text { TOP10-GFP harboring pTra*-CcdA-C2 and pLas- } \\
\text { CcdB-C }\end{array}$ & This study \\
\hline CR01 & $\begin{array}{l}\text { TOP10-RFP harboring pLas-CcdA-C and pTra*- } \\
\text { CcdB-C1 }\end{array}$ & This study \\
\hline CR02 & $\begin{array}{l}\text { TOP10-RFP harboring pLas-CcdA-C and pTra*- } \\
\text { CcdB-C2 }\end{array}$ & This study \\
\hline SG01 & $\begin{array}{l}\text { TOP10-GFP harboring } \mathrm{pTra} \text { *-CcdA-S and pLas- } \\
\text { CcdB-S }\end{array}$ & This study \\
\hline SR01 & $\begin{array}{l}\text { TOP10-RFP harboring pLas-CcdA-S and pTra*- } \\
\text { CcdB-S }\end{array}$ & This study \\
\hline CGi & $\begin{array}{l}\text { TOP10-GFP harboring } \mathrm{pTra} * \text {-CcdA-Ci and pLas- } \\
\text { CcdB-Ci }\end{array}$ & This study \\
\hline CRi & $\begin{array}{l}\text { TOP10-RFP harboring pLas-CcdA-Ci and pTra*- } \\
\text { CcdB-Ci }\end{array}$ & This study \\
\hline SGi & $\begin{array}{l}\text { TOP10-GFP harboring } \mathrm{pTra} * \text {-CcdA-Si and pLas- } \\
\text { CcdB-Si }\end{array}$ & This study \\
\hline SRi & $\begin{array}{l}\text { TOP10-RFP harboring pLas-CcdA-Si and pTra*- } \\
\text { CcdB-Si }\end{array}$ & This study \\
\hline SG00 & $\begin{array}{l}\text { TOP10-GFP harboring pTra*-CcdA-S and pLas- } \\
\text { CcdB-S0 }\end{array}$ & This study \\
\hline SR00 & $\begin{array}{l}\text { TOP10-RFP harboring pLas-CcdA-S and pTra*- } \\
\text { CcdB-S0 }\end{array}$ & This study \\
\hline NG & TOP10-GFP harboring Ara-CcdA and Tet-CcdB & This study \\
\hline
\end{tabular}


Supplementary Table S2. Plasmids used in this study

\begin{tabular}{|c|c|c|}
\hline Plasmids & Relevant characteristics & References \\
\hline pTra*-CedA-C1 & $\begin{array}{l}\mathrm{Cm}^{\mathrm{R}}, \mathrm{P}_{\text {tra*-RBS }} \text { 32-esaI, BBa_J23104-RBS 30- } \\
\operatorname{traR}(W), \mathrm{P}_{\text {tra }^{*}-\mathrm{RBS}} \text { 30-ccdA, ori pBR322 }\end{array}$ & This study \\
\hline pTra*-CedA-C2 & $\begin{array}{l}\mathrm{Cm}^{\mathrm{R}}, \mathrm{P}_{\mathrm{tr}^{*}-\mathrm{RBS}} 33-e s a I, \mathrm{BBa} J 23104-\mathrm{RBS} 30- \\
\quad \operatorname{traR}(W), \mathrm{P}_{\text {tra* }} \text {-RBS 34-ccdA, ori pBR322 }\end{array}$ & This study \\
\hline pLas-CedB-C & $\begin{array}{c}\mathrm{Amp}^{\mathrm{R}}, \mathrm{BBa} \_\mathrm{J} 23104-\mathrm{RBS} 30-\text { las } R, \mathrm{P}_{\text {las }}-\mathrm{RBS} 35- \\
c c d B \text {, ori p15A }\end{array}$ & This study \\
\hline pLas-CedA-C & $\begin{array}{c}\text { Amp }^{R}, \mathrm{P}_{\text {las }}-\mathrm{RBS} \text { 32X-lasI, BBa_J23104-RBS 30- } \\
\text { las } R, \mathrm{P}_{\text {las }}-\mathrm{RBS} 35-c c d A \text {, ori p15A }\end{array}$ & This study \\
\hline pTra*-CcdB-C1 & $\begin{array}{c}\mathrm{Cm}^{\mathrm{R}}, \mathrm{BBa}-\mathrm{J} 23104-\mathrm{RBS} \text { 30-traR(W), } \mathrm{P}_{\text {tra*-RBS }} \\
\text { 30-ccdB, ori pBR322 }\end{array}$ & This study \\
\hline pTra*-CedB-C2 & $\begin{array}{c}\mathrm{Cm}^{\mathrm{R}}, \mathrm{BBa}-\mathrm{J} 23104-\mathrm{RBS} 30-\operatorname{traR}(W), \mathrm{P}_{\text {tra* }} \text {-RBS } \\
\text { 35-ccdB, ori pBR322 }\end{array}$ & This study \\
\hline pTra*-CedA-S & $\begin{array}{c}\mathrm{Cm}^{\mathrm{R}}, \mathrm{BBa} \_\mathrm{J} 23104-\mathrm{RBS} \text { 30-traR }(W), \mathrm{P}_{\text {tra }^{*} \text {-RBS }} \\
\text { 32-ccdA, ori pBR322 }\end{array}$ & This study \\
\hline pLas-CcdB-S & $\begin{array}{c}\mathrm{Amp}^{\mathrm{R}}, \mathrm{P}_{\text {las }}-\mathrm{RBS} \text { 32X-lasI, BBa_J23104-RBS 30- } \\
\text { lasR, } \mathrm{P}_{\text {las }}-\mathrm{RBS} 34-c c d B \text {, ori p15A }\end{array}$ & This study \\
\hline pLas-CedA-S & $\begin{array}{c}\mathrm{Amp}^{\mathrm{R}}, \mathrm{BBa} \_\mathrm{J} 23104-\mathrm{RBS} 30-\text { las } R, \mathrm{P}_{\mathrm{las}} \mathrm{RBS} 30- \\
c c d A \text {, ori p15A }\end{array}$ & This study \\
\hline pTra*-CcdB-S & $\begin{array}{l}\mathrm{Cm}^{\mathrm{R}}, \mathrm{P}_{\text {tra }^{*}-\mathrm{RBS}} 32-e s a I, \mathrm{BBa} J \mathrm{~J} 23104-\mathrm{RBS} 30- \\
\quad \operatorname{traR}(W), \mathrm{P}_{\text {tra }} * \mathrm{RBS} 30-c c d B \text {, ori } \mathrm{pBR} 322\end{array}$ & This study \\
\hline pTra*-CedA-Ci & $\begin{array}{c}\mathrm{Cm}^{\mathrm{R}}, \operatorname{AraC}, \mathrm{P}_{\text {bad }}-\mathrm{RBS} \text { 33-esaI, BBa_J23104-RBS } \\
\text { 30-traR }(W), \mathrm{P}_{\text {tra* }} \text {-RBS 30-ccdA, ori pBR322 }\end{array}$ & This study \\
\hline pLas-CedB-Ci & $\begin{array}{c}\mathrm{Amp}^{\mathrm{R}}, \mathrm{BBa}-\mathrm{J} 23104-\mathrm{RBS} 30-\text { las } R, \mathrm{P}_{\mathrm{las}}-\mathrm{RBS} 35- \\
c c d B, \text { ori p15A }\end{array}$ & This study \\
\hline pTra $^{*}-\mathrm{CcdB}-\mathrm{Ci}$ & $\begin{array}{c}\mathrm{Cm}^{\mathrm{R}}, \mathrm{BBa} \mathrm{J} 23104-\mathrm{RBS} 30-\operatorname{traR}(W), \mathrm{P}_{\text {tra }^{*}-\mathrm{RBS}} \\
30-c c d B \text {, ori pBR322 }\end{array}$ & This study \\
\hline pLas-CedA-Ci & $\begin{array}{l}\text { Amp }^{\mathrm{R}} \text {, TetR, } \mathrm{P}_{\text {tet }} \text {-RBS 32X-lasI, BBa_J23104- } \\
\text { RBS 30-lasR, } \mathrm{P}_{\text {las }}-\mathrm{RBS} 30-c c d A \text {, ori p15A }\end{array}$ & This study \\
\hline pTra*-CedA-Si & $\begin{array}{c}\mathrm{Cm}^{\mathrm{R}}, \mathrm{BBa}{ }_{-}^{\mathrm{J}} 23104-\mathrm{RBS} 30-\operatorname{tra} R(W), \mathrm{P}_{\text {tra* }}{ }^{*} \mathrm{RBS} \\
\text { 64-ccdA, ori pBR322 }\end{array}$ & This study \\
\hline pLas-CcdB-Si & $\begin{array}{l}\text { Amp }^{\mathrm{R}} \text {, TetR, } \mathrm{P}_{\mathrm{te}}-\mathrm{RBS} 32 \mathrm{X}-\text { lasI, BBa_J23104- } \\
\mathrm{RBS} \text { 30-lasR, } \mathrm{P}_{\text {las }}-\mathrm{RBS} \text { 35-ccdB, ori p15A }\end{array}$ & This study \\
\hline pTra*-CcdB-Si & $\begin{array}{c}\mathrm{Cm}^{\mathrm{R}}, \operatorname{AraC}, \mathrm{P}_{\text {bad }}-\mathrm{RBS} \text { 33-esaI, BBa_J23104-RBS } \\
\text { 30-traR }(W), \mathrm{P}_{\text {tra* }} \text {-RBS 30-ccdB, ori pBR322 }\end{array}$ & This study \\
\hline pLas-CedA-Si & $\begin{array}{l}\mathrm{Amp}^{\mathrm{R}}, \mathrm{BBa} \_\mathrm{J} 23104-\mathrm{RBS} 30-\text { las } R, \mathrm{P}_{\mathrm{las}}-\mathrm{RBS} 30- \\
c c d A \text {, ori p15A }\end{array}$ & This study \\
\hline pLas-CcdB-S0 & $\begin{array}{c}\mathrm{Amp}^{\mathrm{R}}, \mathrm{BBa} \mathrm{J} 23104-\mathrm{RBS} 30-\text { las } R, \mathrm{P}_{\text {las }}-\mathrm{RBS} 34- \\
c c d B \text {, ori p15A }\end{array}$ & This study \\
\hline pTra*-CcdB-S0 & 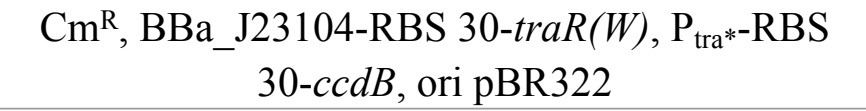 & This study \\
\hline
\end{tabular}




\begin{tabular}{|c|c|c|}
\hline Ara-CcdA & $\mathrm{Cm}^{\mathrm{R}}, \mathrm{AraC}, \mathrm{P}_{\text {bad }^{-}}-c c d A$, ori $\mathrm{pBR} 322$ & This study \\
\hline Tet-CcdB & $\mathrm{Amp}^{\mathrm{R}}, \mathrm{TetR}, \mathrm{P}_{\text {tet }}$-ccdB, ori $\mathrm{p} 15 \mathrm{~A}$ & This study \\
\hline Tet-CcdA & $\mathrm{Amp}^{\mathrm{R}}, \mathrm{TetR}, \mathrm{P}_{\text {tet }}$-ccdA, ori $\mathrm{p} 15 \mathrm{~A}$ & This study \\
\hline Ara-CcdB & $\mathrm{Cm}^{\mathrm{R}}, \mathrm{AraC}, \mathrm{P}_{\text {bad }}-c c d B$, ori pBR322 & This study \\
\hline pAH69 & $\mathrm{pSC101}$ ori, HK022 integrase & 1 \\
\hline pHK & R6K ori, HK022 attp, Kan ${ }^{\mathrm{R}}, \mathrm{FRT}$ & 1 \\
\hline pHK-GFP & R6K ori, HK022 attp, Kan ${ }^{\mathrm{R}}, \mathrm{FRT}, g f p$ & This study \\
\hline pHK-RFP & R6K ori, HK022 attp, Kan ${ }^{\mathrm{R}}, \mathrm{FRT}, r f p$ & This study \\
\hline
\end{tabular}


Supplementary Table S3. RBSs used in this study

\begin{tabular}{|c|r|c|c|}
\hline RBS & Sequences & Strength & Source \\
\hline BBa_B0030 & TCTAGAGATTAAAGAGGAGAAATACTAG $A T G$ & strong & iGEM \\
\hline BBa_B0031 & TCTAGAGTCACACAGGAAACCTACTAG $A T G$ & medium & iGEM \\
\hline BBa_B0032 & TCTAGAGTCACACAGGAAAGTACTAG $A T G$ & medium & iGEM \\
\hline BBa_B0032X & TCTAGAGTCACACAGGAAGATACTAG $A T G$ & medium & 2 \\
\hline BBa_B0033 & TCTAGAGTCACACAGGACTACTAG $A T G$ & weak & iGEM \\
\hline BBa_B0034 & TCTAGAGAAAGAGGAGAAATACTAG $A T G$ & strong & iGEM \\
\hline BBa_B0035 & TCTAGAGATTAAAGAGGAGAATACTAG $A T G$ & strong & iGEM \\
\hline BBa_B0064 & TCTAGAGAAAGAGGGGAAATACTAG $A T G$ & medium & iGEM \\
\hline
\end{tabular}

The sequences of individual RBS are shown in bold. The start codon of the downstream coding sequence is shown in italic. 
Supplementary Table S4. Promoters used in this study

\begin{tabular}{|c|l|}
\hline Promoters & \multicolumn{1}{|c|}{ Sequences } \\
\hline $\mathbf{P}_{\text {las }}$ & $\begin{array}{l}\text { TTCGAGCCTAGCAAGGGTCCGGGTTCACCGAAATCTATCTCATTT } \\
\text { GCTAGTTATAAAATTATGAAATTTGCGTAAATTCTTCA }\end{array}$ \\
\hline $\mathbf{P}_{\text {tra* }}$ & $\begin{array}{l}\text { GCACGTGCAGATCTGCACATTTACGCAAGAAAATGGTTTGTTATA } \\
\text { GTCGAATAT }\end{array}$ \\
\hline $\mathbf{P}_{\text {tet* }}$ & $\begin{array}{l}\text { TTTTCAGCAGGACGCACTGACCTCCCTATCAGTGATAGAGATTGA } \\
\text { CATCCCTATCAGTGATAGAGATACTGAGCACCTCG }\end{array}$ \\
\hline $\mathbf{P}_{\mathbf{b a d}}$ & $\begin{array}{l}\text { AAAGCCATGACAAAAACGCGTAACAAAAGTGTCTATAATCACGG } \\
\text { TGCCATAGCATTTTTATCCATAAGATTAGCGGATCCTACCTGACG }\end{array}$ \\
\hline BBa_J23104 & CTTTTTATCGCAACTCTCTACTGTTTCTCCAT \\
\hline
\end{tabular}

J23104 is derived from http://parts.igem.org/Main_Page. 
Supplementary Table S5. The combinations of inducers used in the inducible synthetic ecosystems to control the proportion of population

\begin{tabular}{|c|c|c|c|c|}
\hline Inducers Combinations & I & II & III & IV \\
\hline Ara $(\mu \mathrm{M})$ & 0 & 66 & 330 & 1300 \\
\hline aTc $(\mathrm{ng} / \mathrm{ml})$ & 1000 & 1 & 0.1 & 0 \\
\hline
\end{tabular}


a

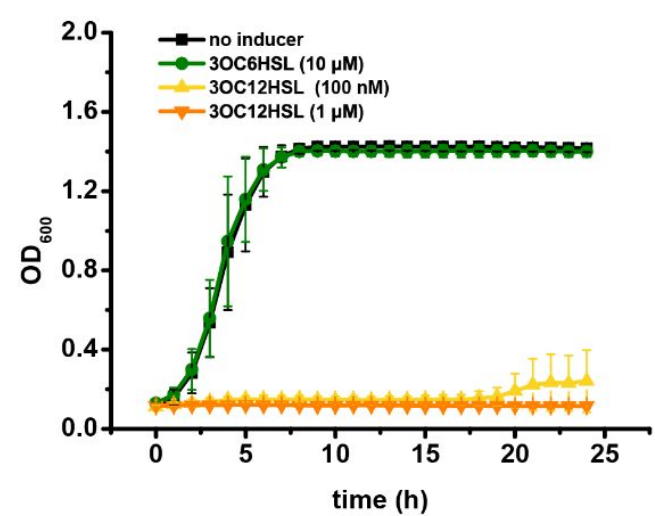

C

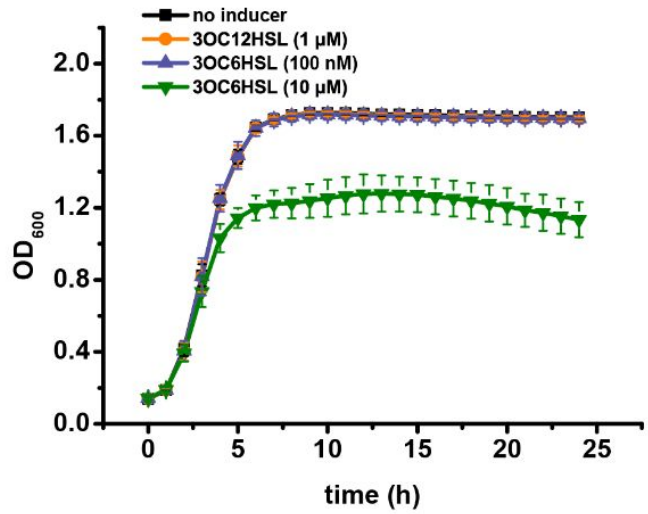

b
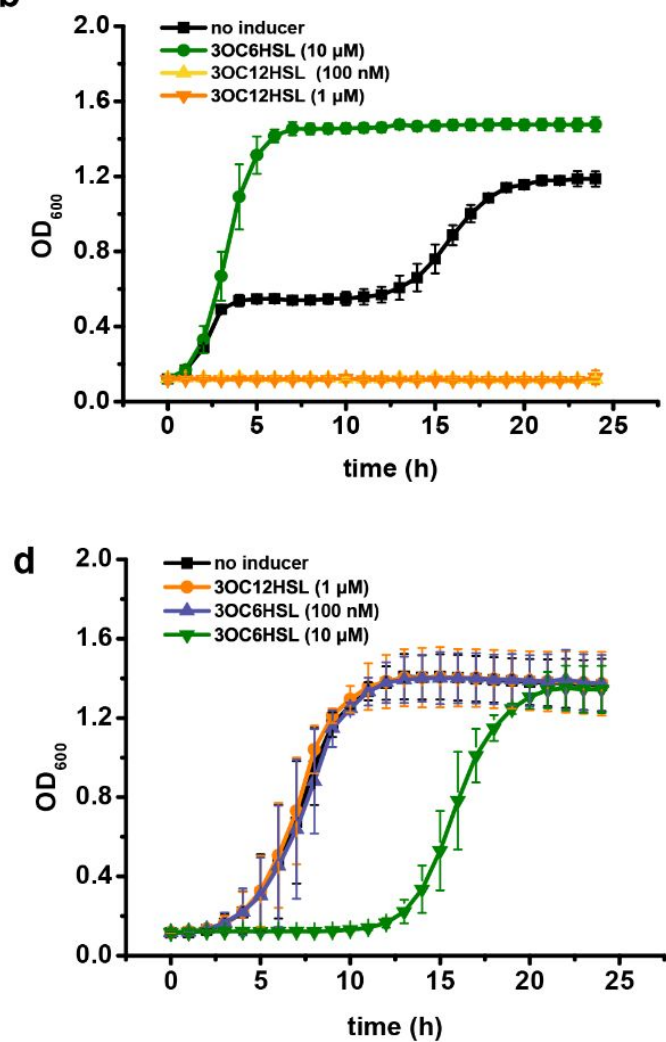

Supplementary Figure S1. Growth characterization of single strains in synthetic competitive ecosystem. (a) Characterization of CG01. 3OC6HSL induces the expression of CcdA; 3OC12HSL induces the expression of CcdB. (b) Characterization of CG02. 3OC6HSL induces the expression of CcdA; 3OC12HSL induces the expression of CcdB. (c) Characterization of CR01. 3OC6HSL induces the expression of CcdB; 3OC12HSL induces the expression of CcdA. (d) Characterization of CR02. 3OC6HSL induces the expression of CcdB; 3OC12HSL induces the expression of CcdA. Data show the means \pm SD of three experiments. 

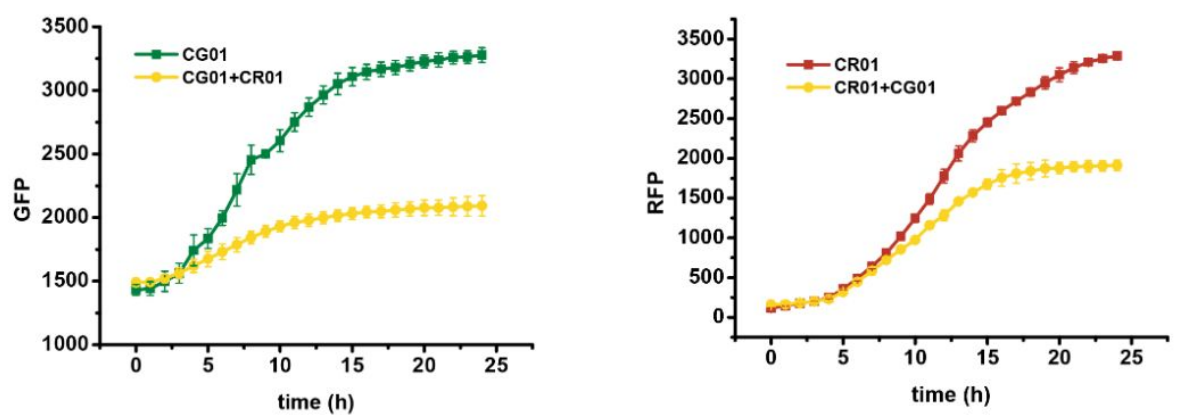

CG01+CR02
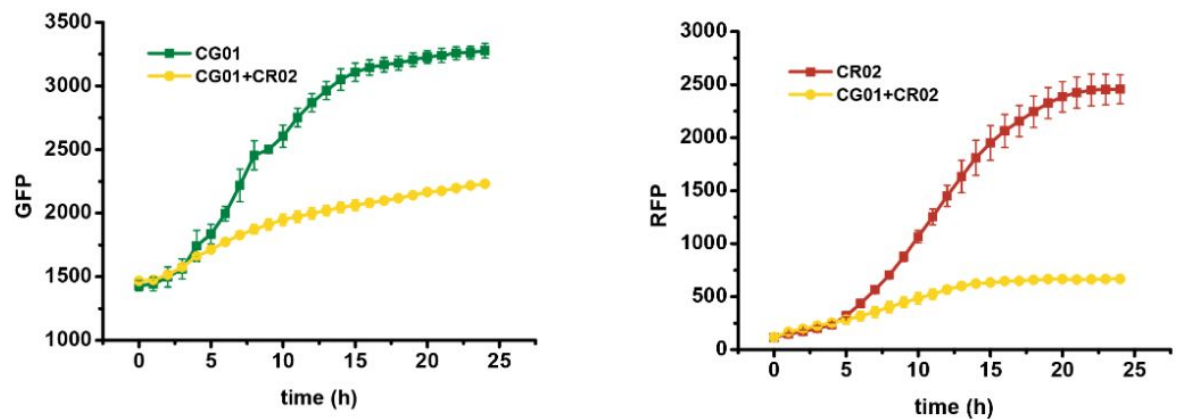

CG02+CR01
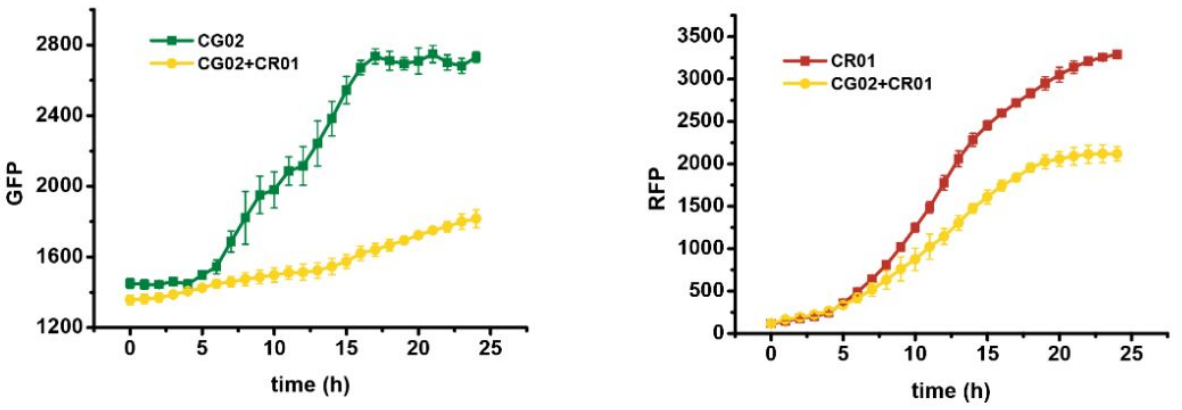

CG02+CR02
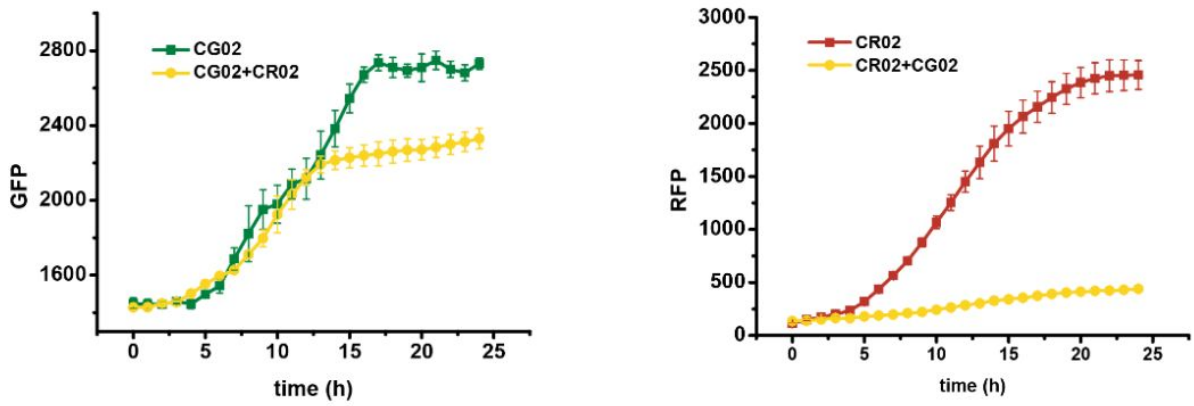

Supplementary Figure S2. Co-culture of strains CG and CR in liquid medium. Four combinations were generated by pair-to-pair co-culture of CG and CR. The left column represents GFP expression. The right column represents RFP expression. Data show the means \pm SD of three experiments. 


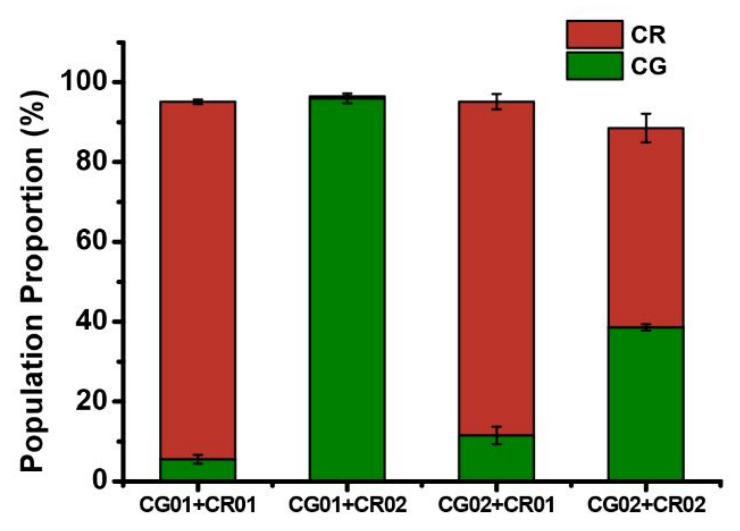

Supplementary Figure S3. Population proportion of CG and CR co-culture systems.

Two strains in each combination are inoculated in a ratio of $1: 1$. Proportion of strains are analyzed after 24 hours. Data show the means \pm SD of three experiments. 


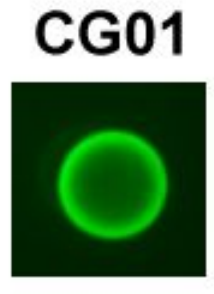

\section{CR01}

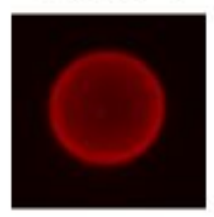

\section{CG02}

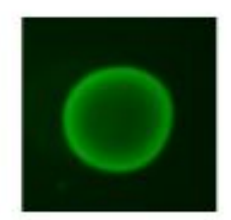

CR02

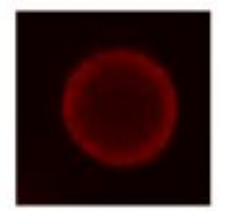

Supplementary Figure S4. Characterization of single CG and CR strains on agar plate. 


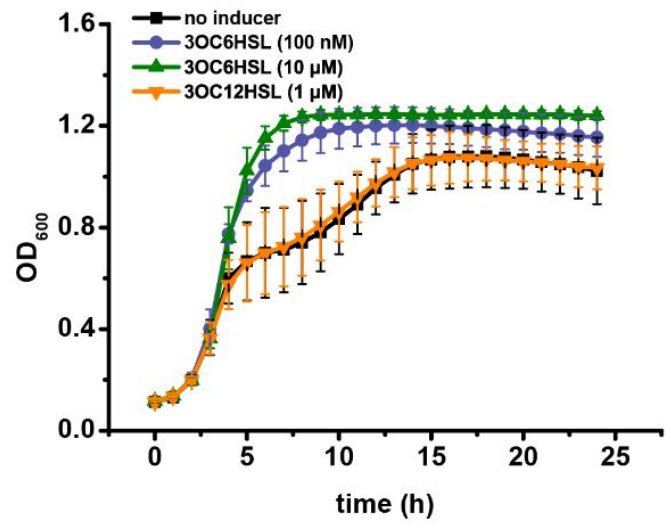

b

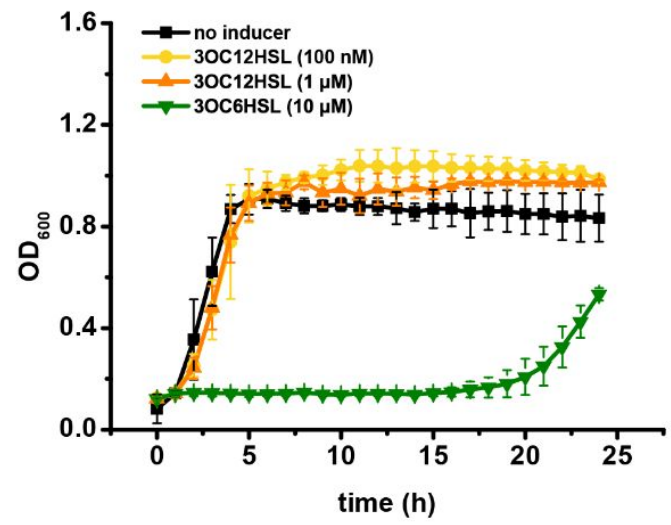

Supplementary Figure S5. Growth characterization of single strains in synthetic symbiotic ecosystem. (a) Characterization of SG01. 30C6HSL induces the expression of CcdA; 3OC12HSL induces the expression of CcdB. (b) Characterization of SR01. 3OC6HSL induces the expression of CcdB; 3OC12HSL induces the expression of CcdA. Data show the means $\pm \mathrm{SD}$ of three experiments. 
a

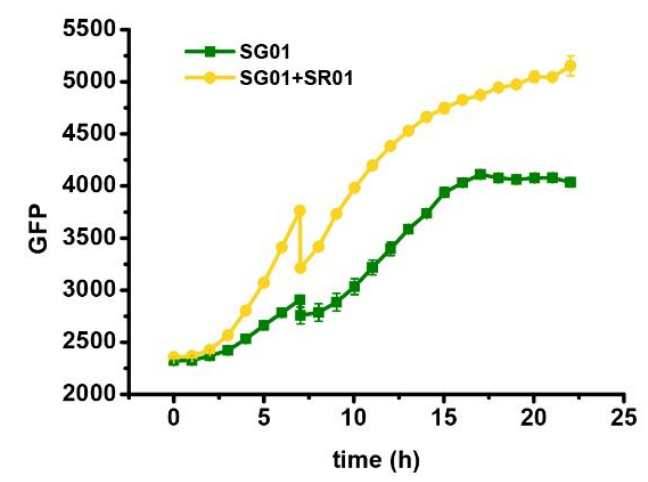

b

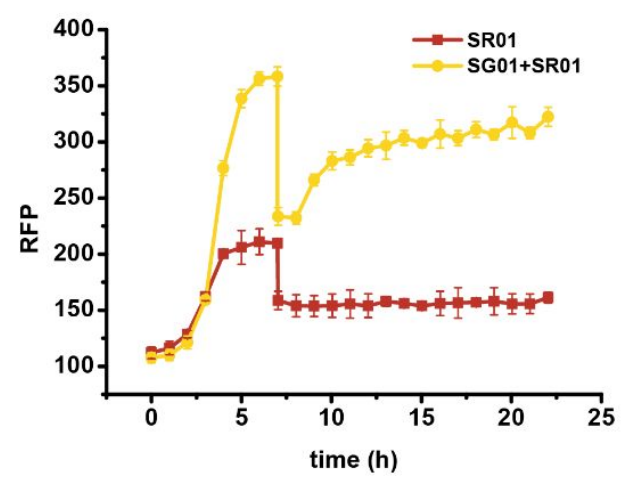

Supplementary Figure S6. Dilution experiment of co-culture symbiotic ecosystem. The co-culture system was diluted twice at $7 \mathrm{~h}$. (a) GFP expression of SG01. Green line indicates single strain SG01; yellow line indicates co-culture of SG01 and SR01. (b) RFP expression of SR01. Red line indicates single strain SR01; yellow line indicates co-culture of SG01 and SR01. Data show the means \pm SD of three experiments. 
a

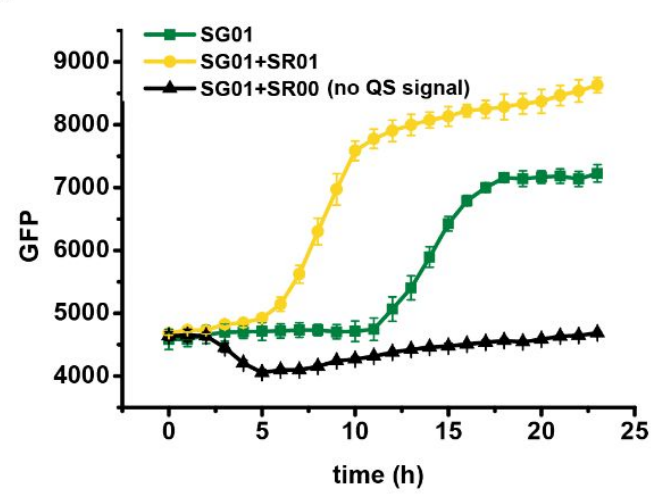

b

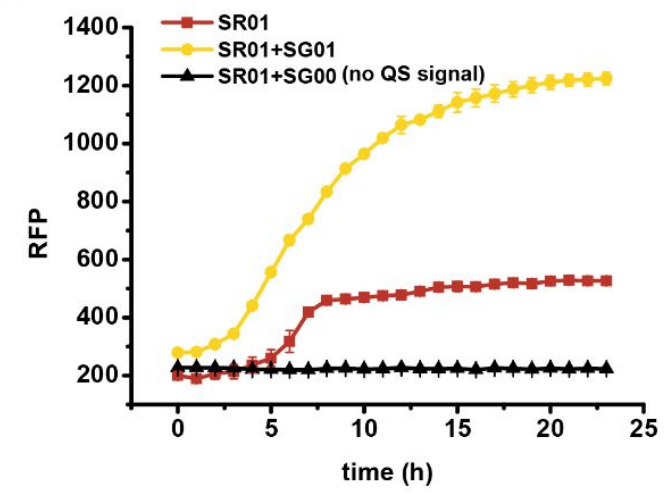

Supplementary Figure S7. Control experiments of synthetic symbiotic ecosystems. SG00 and SR00 are obtained by removing HSL synthase from SG01 and SG01, respectively. Both SG01 and SR01 cannot grow when they co-cultured with strain that cannot produce signals. (a) GFP expression of SG01. Green line indicates single strain SG01; yellow line indicates the co-culture of SG01 and SR01; black line indicates the co-culture of SG01 and SR00. (b) RFP expression of SR01. Red line indicates single strain SR01; yellow line indicates the co-culture of SR01 and SG01; black line indicates the co-culture of SR01 and SG00. Data show the means \pm SD of three experiments. 
$\square$ SR01 घSG01

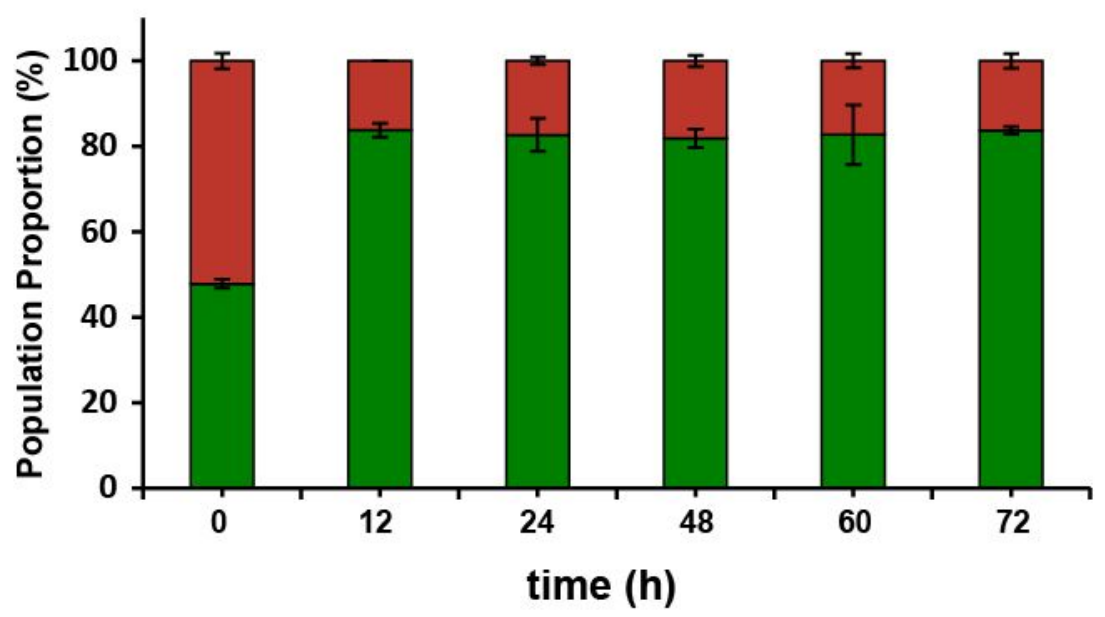

Supplementary Figure S8. Population proportion of SG01 and SR01 co-culture system. Data show the means $\pm \mathrm{SD}$ of three experiments. 


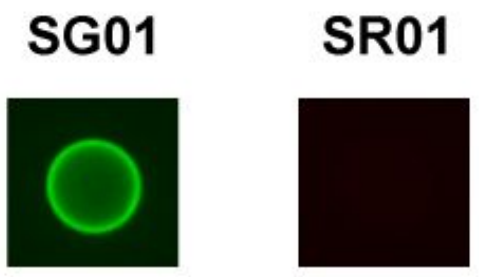

Supplementary Figure S9. Characterization of single SG and SR strains on agar plate. 
a

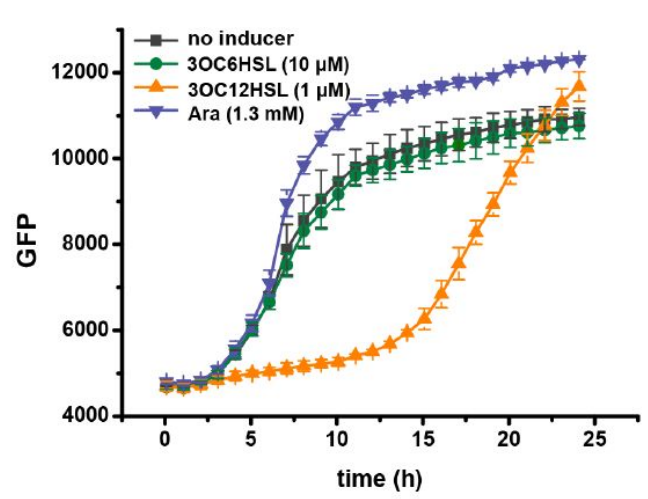

C

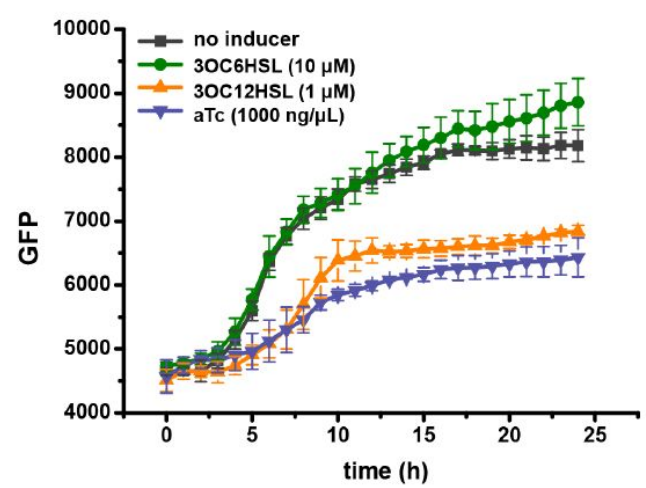

b

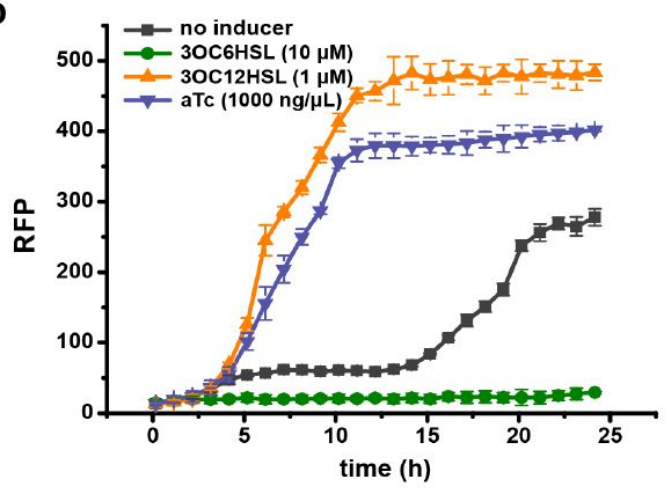

d

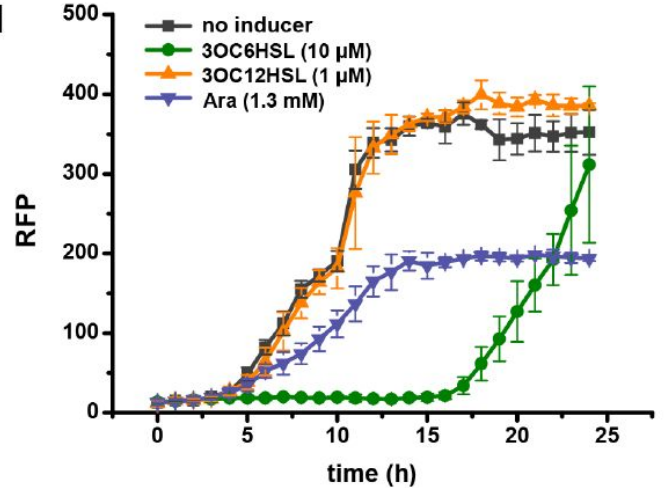

Supplementary Figure S10. Characterization of single strains in inducible synthetic ecosystems. (a) characterization of CGi. (b) characterization of CRi. (c) characterization of SGi. (d) characterization of SRi. Data show the means $\pm \mathrm{SD}$ of three experiments. 


\section{Ara}
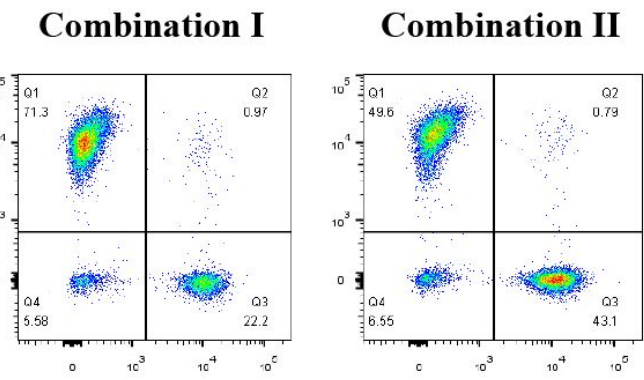

\section{Combination III}

\section{Combination IV}
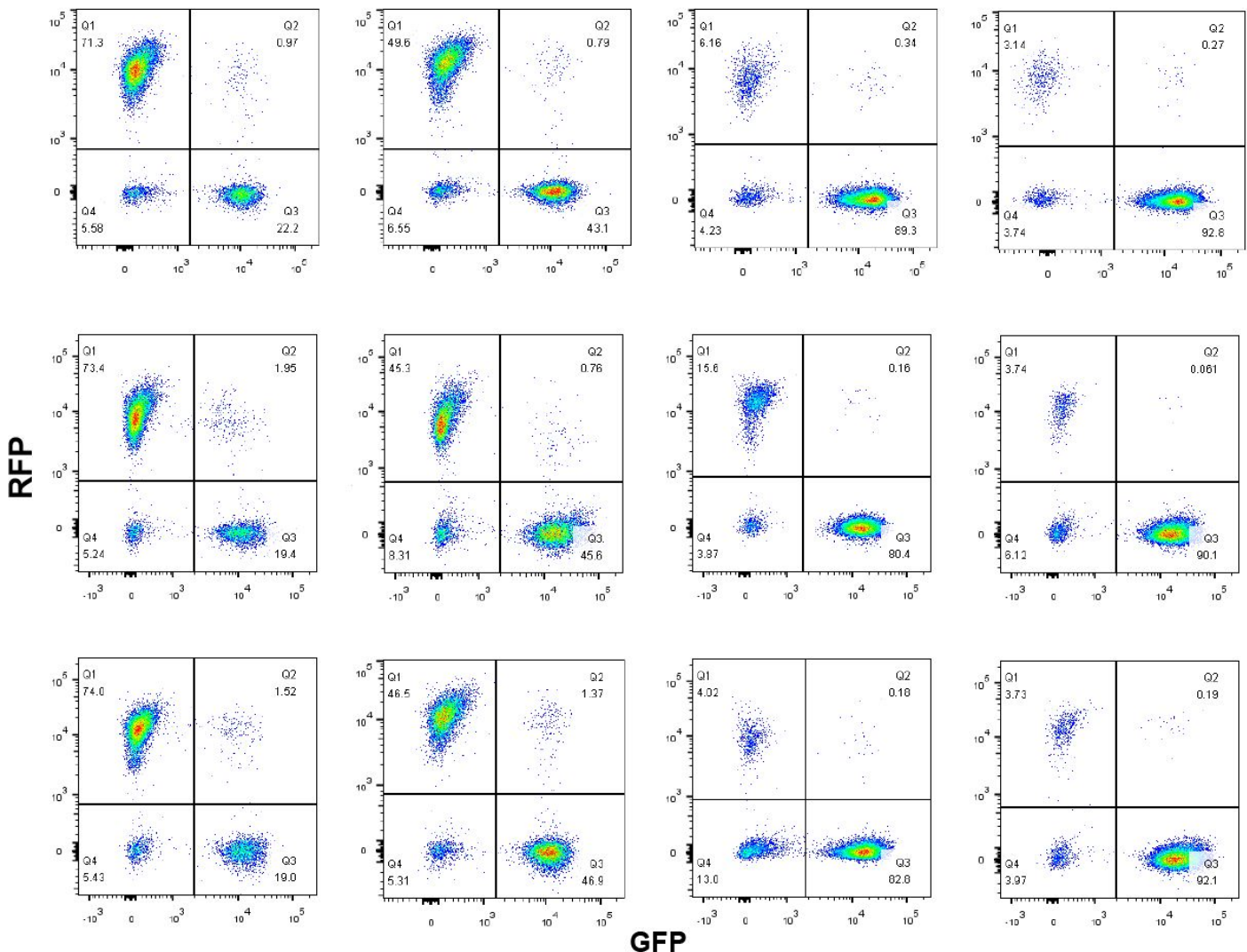

aTc

Supplementary Figure S11. Population regulation by inducible synthetic competitive ecosystem. Three rows represent three independent replicates. Events in quadrant Q1 represent strains express RFP. Events in quadrant Q3 represent strains express GFP. Events in quadrant Q4 are impurities and dead cells. 
Ara

\section{Combination I}
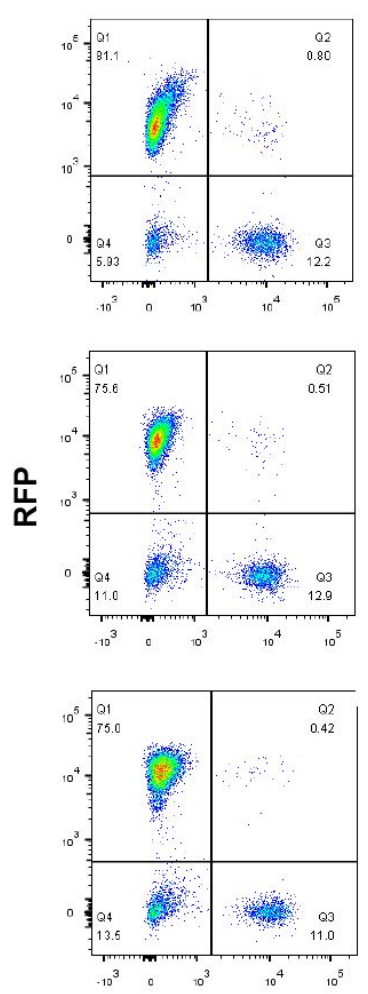

Combination II
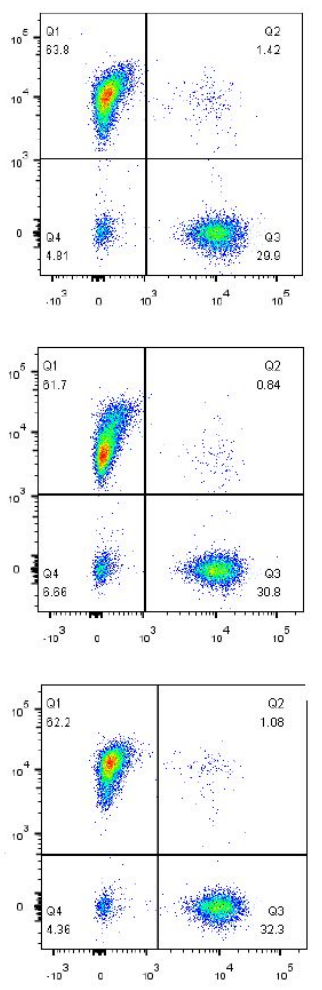

Combination III
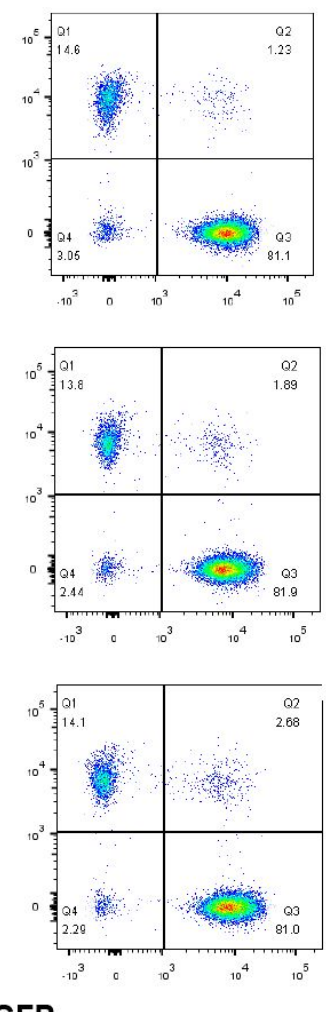

GFP

\section{Combination IV}
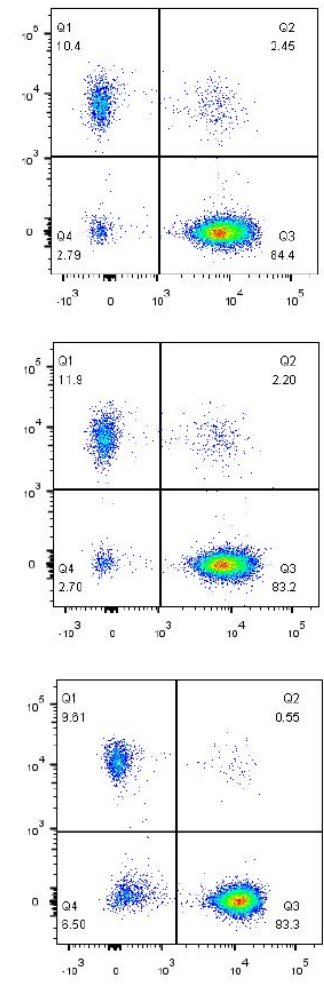

aTc

Supplementary Figure S12. Population regulation by inducible synthetic symbiotic ecosystem. Three rows represent three independent replicates. Events in quadrant Q1 represent strains express RFP. Events in quadrant Q3 represent strains express GFP. Events in quadrant Q4 are impurities and dead cells. 

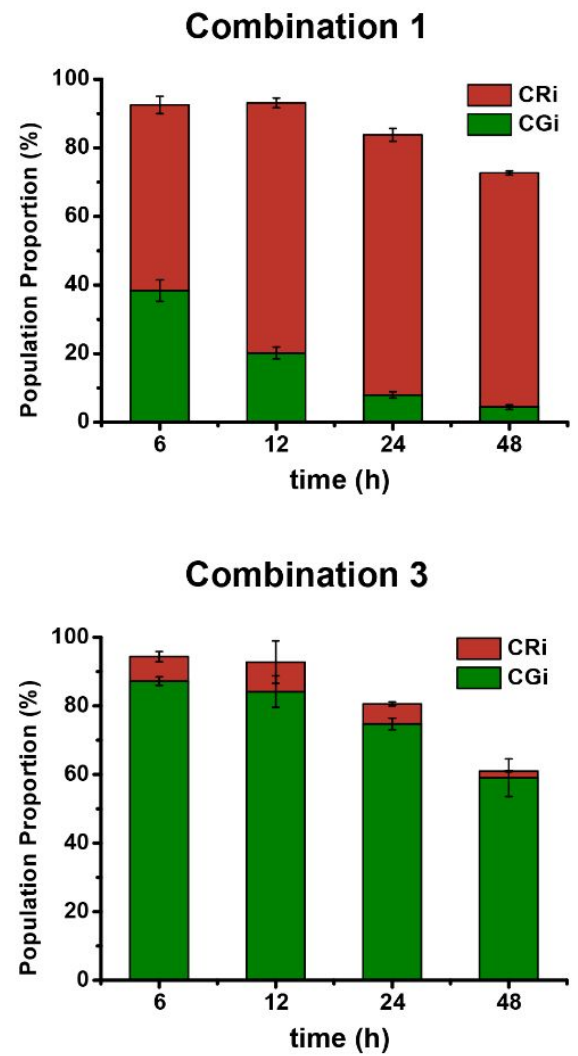

Combination 2

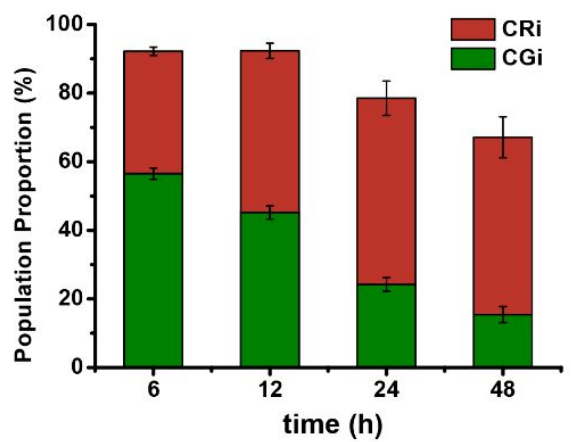

Combination 4

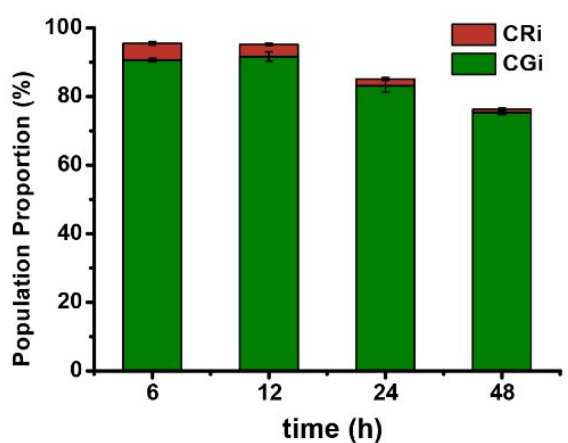

Supplementary Figure S13. Time-course population proportion variation of inducible synthetic competitive ecosystem. Combination 1 to Combination 4 are different inducers combinations. Data show the means $\pm \mathrm{SD}$ of three experiments. 


\section{Combination 1}

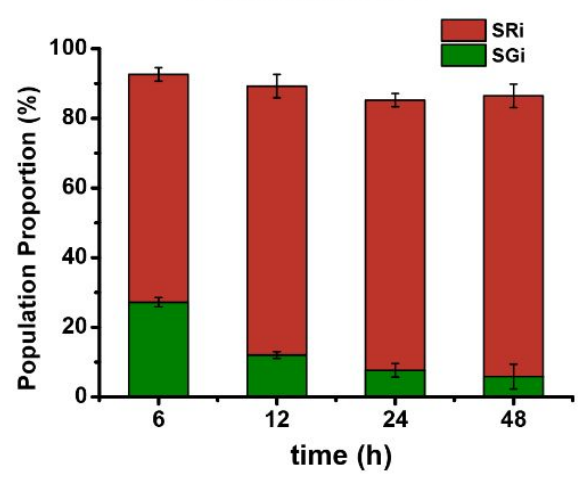

Combination 3

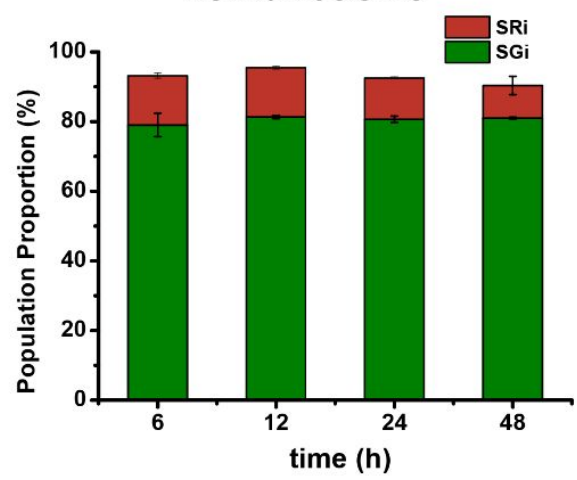

Combination 2

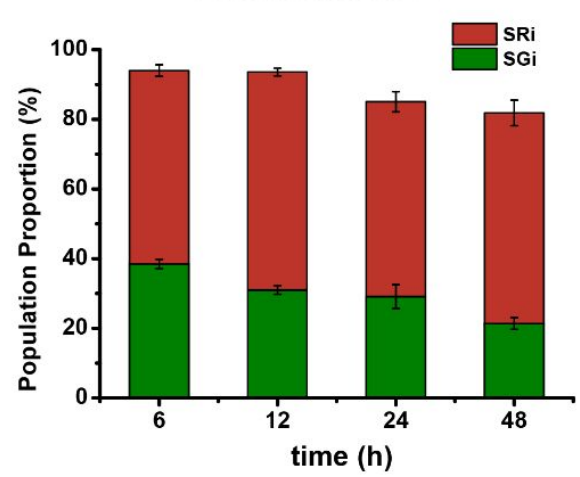

Combination 4

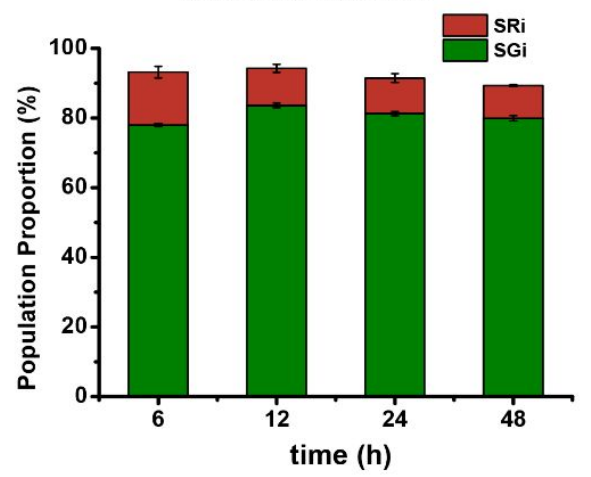

Supplementary Figure S14. Time-course population proportion variation of inducible synthetic symbiotic ecosystem. Combination 1 to Combination 4 are different inducers combinations. Data show the means $\pm \mathrm{SD}$ of three experiments. 
a
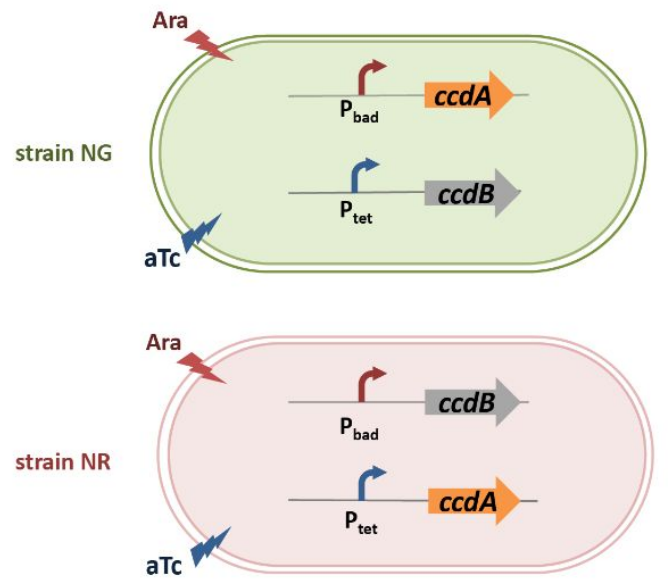

b

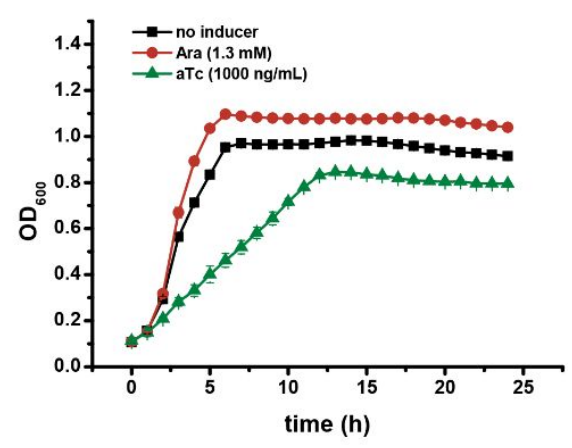

C

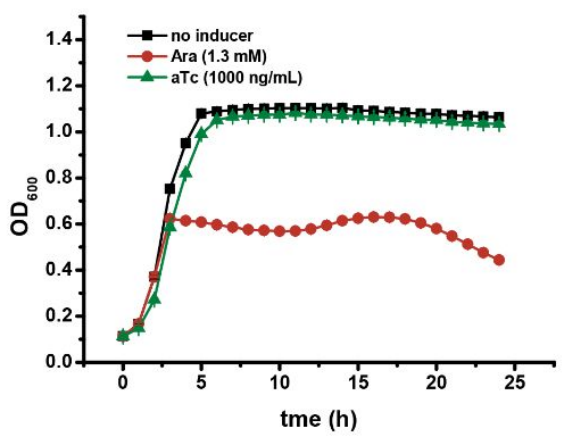

Supplementary Figure S15. Design and characterization of the No QS Control system.

(a) Design of the No QS Control system. (b) Characterization of NG. (c) Characterization of NR. Data show the means \pm SD of three experiments. 
a

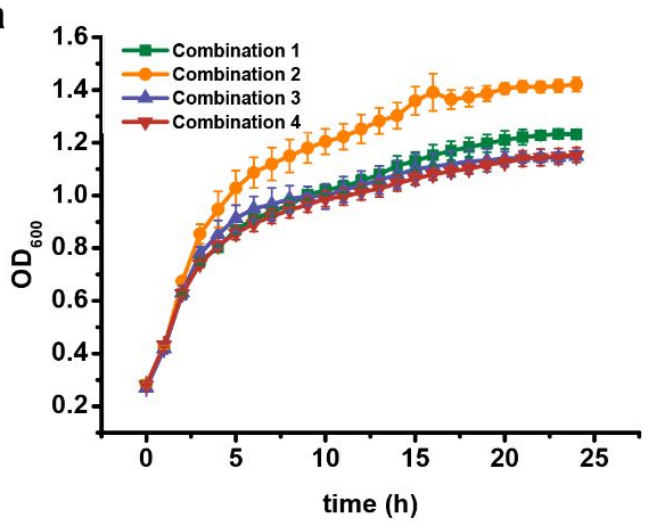

b

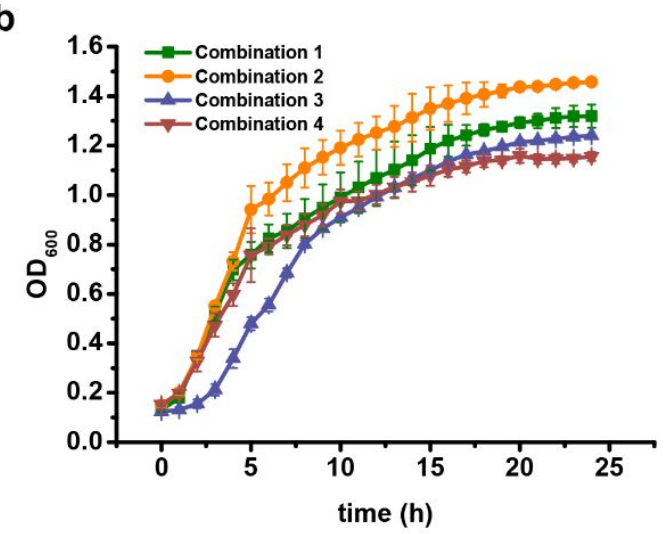

C

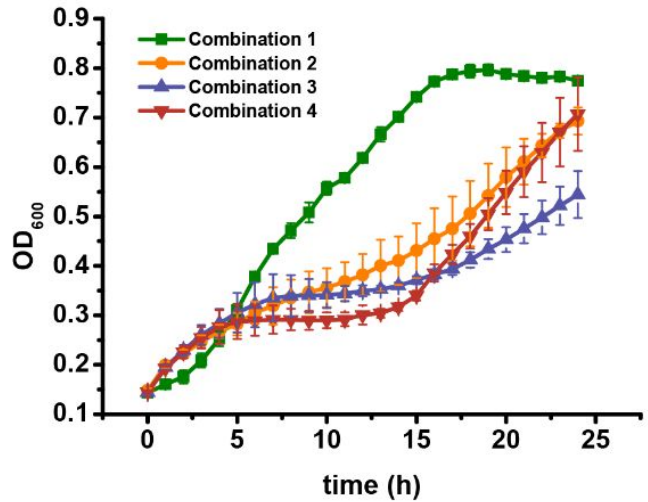

Supplementary Figure S16. Coculture growth curve of inducible synthetic ecosystems and No QS Control system. (a) Coculture growth curve of inducible synthetic competitive system. (b) Coculture growth curve of inducible synthetic symbiotic system. (c) Coculture growth curve of the No QS Control system. Combination 1 to Combination 4 are different inducer combinations. Data show the means $\pm \mathrm{SD}$ of three experiments. 

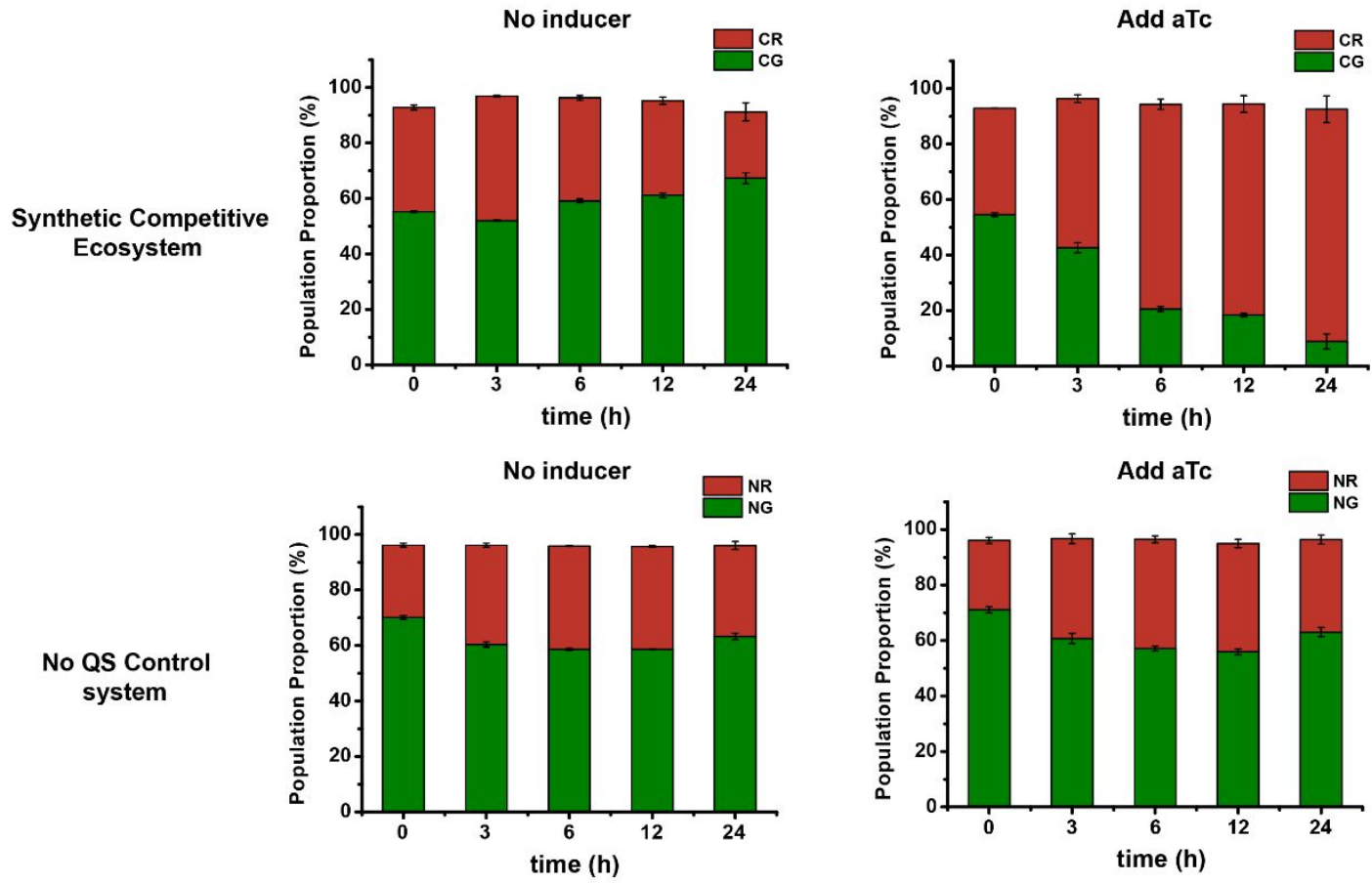

Supplementary Figure S17. Switching of the dominant strain in the synthetic competitive ecosystem and the No QS Control system. GFP and RFP strains are inoculated in a ratio about 3:1. $1000 \mathrm{ng} / \mathrm{ml}$ aTc are added after $1 \mathrm{~h}$. No inducer groups are the control experiments of two systems. Population proportions are analyzed by flow cytometer. Data show the means \pm SD of three experiments. 


\section{Reference}

1. Haldimann, A., and Wanner, B. L. (2001) Conditional-replication, integration, excision, and retrieval plasmid-host systems for gene structure-function studies of bacteria, Journal of bacteriology 183, 6384-6393.

2. Jiang, W., He, X. Y., Luo, Y., Mu, Y. L., Gu, F., Liang, Q. F., and Qi, Q. S. (2020) Two Completely Orthogonal Quorum Sensing Systems with Self-Produced Autoinducers Enable Automatic Delayed Cascade Control, Acs Synth Biol 9, 2588-2599. 